\title{
DNA polymerase beta overexpression correlates with poor prognosis in esophageal cancer patients
}

\author{
ZHENG Hong $^{1 \dagger}$, XUE Peng ${ }^{1 \dagger}$, LI Min ${ }^{2}$, ZHAO JiMin², DONG ZiMing ${ }^{2 *} \&$ ZHAO GuoQiang $^{2 *}$ \\ ${ }^{1}$ Department of Pathophysiology, Medical College of Henan University, Kaifeng 475004, China; \\ ${ }^{2}$ School of Basic Medical Sciences, Zhengzhou University, Zhengzhou 450001, China
}

Received March 26, 2013; accepted May 17, 2013; published online July 17, 2013

\begin{abstract}
Gene of DNA polymerase beta (pol $\beta$ ) plays an important role in base excision repair, DNA replication and translesion synthesis. This study aims to investigate the expression and prognostic significance of DNA pol $\beta$ in esophageal cancer. DNA pol $\beta$ expression was analyzed using real-time quantitative PCR (RT-qPCR) and immunohistochemical staining on tissue samples from a consecutive series of 114 esophageal squamous carcinoma patients who underwent resections between 2002 and 2006 . Pol $\beta$ expression was investigated on its correlation to clinico-pathological factors and survival. RT-qPCR results showed higher expression of DNA pol $\beta$ mRNA in tumor tissue than in its matched adjacent non-tumor tissue sample, different expression of DNA pol $\beta$ mRNA was noticed with significance between tumors with and without lymph node metastasis. Immunohistochemistry staining results indicated the pol $\beta$ strong-positive rate was $44.73 \%$ (51/114) in tumor tissue samples and $0.00 \%$ in matched adjacent non-tumor tissue samples, with significant difference. Kaplan-Meier survival curves revealed that high expression of pol $\beta$ was associated with tumor metastasis and poor prognosis in esophageal cancer patients. Our data suggests that pol $\beta$ plays an important role in tumor progression and that high pol $\beta$ expression predicts an unfavorable prognosis in esophageal squamous carcinoma patients.
\end{abstract}

esophageal carcinoma, DNA polymerase beta, tumor metastasis, survival time

Citation: Zheng H, Xue P, Li M, et al. DNA polymerase beta overexpression correlates with poor prognosis in esophageal cancer patients. Chin Sci Bull, 2013, 58: 3274-3279, doi: 10.1007/s11434-013-5956-2

Esophageal cancer (EC), one of the most common malignancies threatening human health, is characterized in the significant difference in regional distribution in epidemiology. EC patients newly diagnosed each year in China account for more than half of all EC cases across the world $[1,2]$. Another important feature of EC is its high mortality, most EC patients succumb to metastasis and eventual death despite of radical resection and multi-modality therapies applied $[3,4]$.

In tumor molecular genetics, it is well-known that carcinogenesis is a multi-stage process with variation in multiple genes. Endogenous or exogenous detrimental factors may induce DNA damage and mutation constituting the

$\dagger$ These authors contributed equally to this work.

*Corresponding authors (email: zhaogq@zzu.edu.cn; dongzm@zzu.edu.cn) genetic basis of neoplastic pathogenesis. DNA polymerase beta ( $p o l \beta)$, found widely in nucleus of mammalian cells, is a small-molecular protein $\left(\mathrm{M}_{\mathrm{r}}: 39 \mathrm{kD}\right)$ with a single peptide chain. Consisting of 355 amino acid residues, this small DNA polymerase plays a vital role in base excision repair, DNA replication and translesion synthesis [5-7]. Given its poor fidelity in synthesizing DNA, pol $\beta$ may be one of the causes of genomic instability when it is highly expressed and therefore participates probably in DNA replication, permits the duplication of the mistaken DNA, and induces mutation in a static cell $[8,9]$. Recent researches imply that the obviously higher expression of pol $\beta$ correlates closely to carcinogenesis and development either in vivo or in vitro in multiple malignancies [10-12]. Our study is the first to report that DNA pol $\beta$ correlates with worse survival of EC patients, which may provide a new idea for prevention and 
treatment of EC.

\section{Materials and methods}

\subsection{Patients and samples}

EC samples (114 samples) were collected after esophagectomy from 3 hospitals including Oncology Hospital of Linzhou, People's Hospital of Linzhou and the 1st Hospital Affiliated to Zhengzhou University. All tumors were histopathologically confirmed to be squamous cell carcinoma and none of patients have received any therapies before surgery. The mean age of EC in our study was 59.56 \pm 8.67 . The matched adjacent esophageal mucosae samples at least $5 \mathrm{~cm}$ away from the tumor borderline were collected as well. All samples were snap-frozen and kept in liquid nitrogen. All patients signed the informed consent before collecting samples. This study was approved by Ethical Committee of Zhengzhou University.

\subsection{Real-time quantitative PCR (RT-qPCR) analysis}

Total RNA was extracted from EC and matched adjacent tissue samples using TRIZOL (Invitrogen, CA). Reverse transcription was performd with $6 \mu \mathrm{L} 5 \times$ Buffer, $1 \mu \mathrm{L}$ RNasin, $2 \mu \mathrm{L} 4 \times \mathrm{dNTP}\left(2.5 \mathrm{mmol} \mathrm{L}^{-1}\right), 1 \mu \mathrm{L}$ Oligo6 $\left(10 \mu \mathrm{mol} \mathrm{L}^{-1}\right)$, $1 \mu \mathrm{L}$ AMV $\left(10 \mathrm{U}_{\mu} \mathrm{L}^{-1}\right), 5 \mu \mathrm{L}$ RNA template and $14 \mu \mathrm{L}$ DEPC water according to protocols provided by the supplier. Quantitative real-time PCR was carried out in a $50-\mu \mathrm{L}$ reaction system including $25 \mu \mathrm{L} 2 \times \mathrm{SYBR}^{\circledR}$ Premix Ex Taq enzyme (TaKaRa, Japan), $1 \mu \mathrm{L}$ forward and $1 \mu \mathrm{L}$ reverse primer for pol $\beta$ (5'-ACGTAAACTGGAAAAGATTCGGC3', 5'-GCCCAATTCGCTGATGATGGTTC-3'), $1 \mu \mathrm{L}$ 50× ROX Reference Dye (Roche, USA), $4 \mu \mathrm{L}$ cDNA template, $18 \mu \mathrm{L}$ DEPC water. PCR parameters included pre-denature at $95^{\circ} \mathrm{C}$ for $3 \mathrm{~min}, 95^{\circ} \mathrm{C}$ for $20 \mathrm{~s}$ and $60^{\circ} \mathrm{C}$ for $60 \mathrm{~s}$ for 40 cycles, and terminal extension for $10 \mathrm{~min}$. The primers for $\beta$-actin were 5'-TGACCCAGATCATGTTTGAG-3' and 5'-TGGCATGGGGGAGGGCATAC-3' for sense and antisense respectively. The amplified $\mathrm{CT}$ value was recorded to quantify the copies of the gene. The copy ratio of pol $\beta$ and $\beta$-actin were presented as the relative expression of pol $\beta$.

\subsection{Immunohistochemistry assay}

One hundred and fourteen EC and matched adjacent tissue samples were fixed with $10 \%$ neutral methanol, embedded with paraffin and cut into $5 \mu \mathrm{m}$ slides for IHC (immunohistochemistry) analysis. IHC was performed using streptavidin-perosidase method (SP method) according to instruction provided by the supplier. Rabbit anti-human pol $\beta$ antibody from Santa Cruz (sc-48819)was used at 1:300 working concentration. The slides after 1st and 2nd antibody was developed with DAB, re-stained with hematoxylin, dehydrated, hyalinized, and sealed. Negative control was done with normal rabbit serum instead of 1st antibody and blank control was done with PBS. For immunostaining scoring, 10 high power fields were chosen randomly to count a total of 100 cells in each field. For the percentage of positive cells, it was negative or " 0 " if positive cells less than $5 \%, 1$ for $6 \%-25 \%, 2$ for $26 \%-50 \%, 3$ for $51 \%-70 \%$, and 4 for $>75 \%$. For intensity evalution, it was " 0 " for negative staining, 1 for cells stained lemon yellow, 2 for yellow, and 3 for pale brown. The product of the two scores was classified into four levels: the negative for product 0 , weak positive $(+)$ for $1-4$, positive $(++)$ for $5-8$, strong positive $(+++)$ for 9-12.

\subsection{Follow-up of EC patients}

All patients after surgery were followed up. The overall survival was defined as the period from surgery to last follow up, or to death. The follow up ended at June 2012 with a mean follow-up period of 59.2 months.

\subsection{Statistical analysis}

SPSS 17.0 was used for statistical analysis. Data obtained was presented as mean \pm standard deviation $(\bar{x} \pm \mathrm{SD}) . T$-test was used to compare the average of two samples. Chi-square test was used to compare the ratio of the two samples. Logistic regression analysis was used to evaluate the correlation of pol $\beta$ mRNA with lymph node metastasis in EC. KaplanMeier analysis was used to plot the curve of survival. Cox model was used for the multiple-factor prognostic analysis. $P$-value of less than 0.05 was considered as significant.

\section{Results}

\subsection{Pol $\beta$ mRNA expression in EC}

Using RT-qPCR, we measured pol $\beta$ mRNA expression in 114 EC and matched adjacent esophageal tissue. The pol $\beta$ mRNA expression in EC $(0.440 \pm 0.049)$ was significantly higher than the level of esophageal mucosae $(0.148 \pm 0.020)$ $(t=58.37, P<0.001)$. In EC with lymph node metastasis, furthermore, the level of pol $\beta$ mRNA expression increased significantly as well compared with EC without lymph node involvement $(P<0.001)$. In different stages of EC (TNMG I, II, III), the difference of pol $\beta$ mRNA is significant $(P<$ $0.001)$. There was no difference between age and sex $(P>$ 0.05) (Figure 1).

\subsection{Pol $\beta$ protein expression in EC}

We performed IHC for $114 \mathrm{EC}$ and matched adjacent esophageal tissue samples. The immunoreactivity of pol $\beta$ was yellow to brownish and mainly localized in the nuclei of cancer cells. In the focus tissue of EC, strong immunostaining 


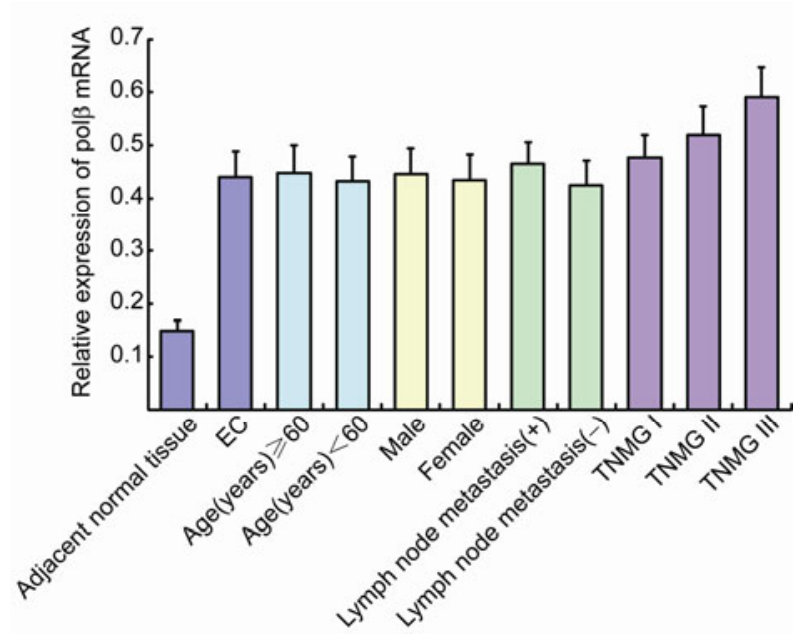

Figure 1 Relative expression of pol $\beta$ mRNA in samples. $P$-value of less than 0.05 was considered as significant.

signal was present in the front of invasive malignant cells with pleomorphism, in particular giant neoplastic cells with multinuclei, and relatively weaker signals were located in the cancer pearl cells. In matched normal tissue, weak immunostaining was mainly localized in the basal cells of epithelium (Figure 2). The positive expression rate of pol $\beta$ protein was $100 \%$ in $114 \mathrm{EC}$ and the matched adjacent normal tissue samples. The strong positive rate of pol $\beta$ protein was $44.73 \%$ in EC samples, significantly higher than that in the matched adjacent esophageal tissue samples. Furthermore, the strong positive rate of $\operatorname{pol} \beta$ protein was $66.67 \%$ in EC with lymph node metastasis, with a significant increase compared with EC without lymph node involvement (Table 1).

\subsection{Survival analysis of EC patients}

Kaplan-Meier survival curve was plotted through sorting the follow-up data of the 114 patients, to analyze the relationship between the expression of pol $\beta$ and age, sex, or lymph node metastasis. Log-rank test revealed a significant difference in survival between subjects with and without lymph node metastasis $\left(\chi^{2}=12.681, P<0.001\right.$, Figure 3(a)) and between those with,+++ and +++ in $\operatorname{pol} \beta$ protein expression $\left(\chi^{2}=\right.$ 59.987, $P<0.001$, Figure 3(b)), but no statistical difference was found between those with different sexes $\left(\chi^{2}=1.263, P=\right.$ 0.261 , Figure $3(\mathrm{c}))$ or ages $\left(\geqslant 60\right.$ years and $<60$ years) $\left(\chi^{2}=\right.$ $1.179, P=0.278$, Figure 3(d)).

COX univariate regression analysis suggested the risk factors in survival of esophageal cancer patients included the presence of lymph node metastasis (Wald $\chi^{2}=11.872$, $P=0.001$ )and the high expression in either pol $\beta$ mRNA (Wald $\chi^{2}=93.734, P<0.001$ ) or pol $\beta$ protein (Wald $\chi^{2}=45.069$, $P<0.001$ ), but not sex (Wald $\chi^{2}=1.219, P=0.270$ ) or age
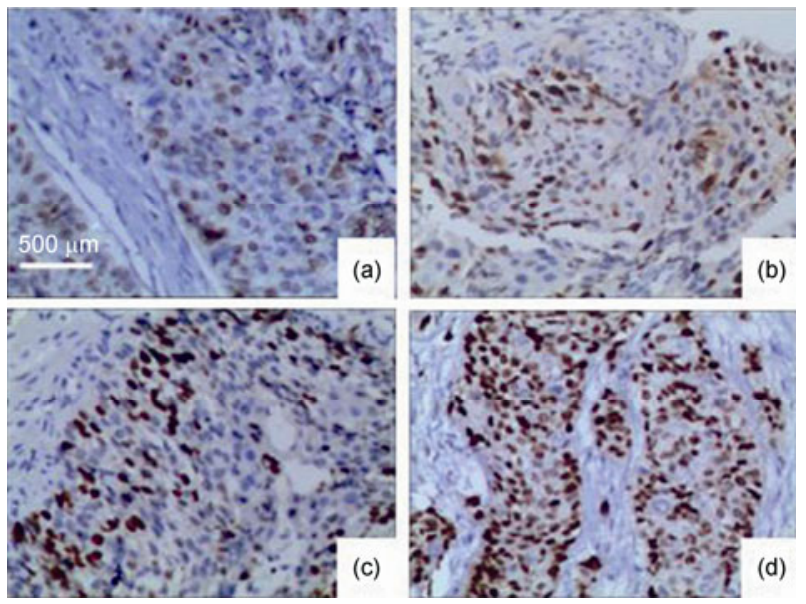

Figure 2 Immunohistochemistry staining of pol $\beta$ in EC and matched adjacent esophageal tissue. Adjacent normal esophageal tissue (+) (a). EC of lower invasion showed weaker yellow signals $(+)(b)$. EC of mean invasion showed brownish signals $(++)(c)$, EC of higher invasion (d) showed strong brownish signals $(+++)$. Bar $=500 \mu \mathrm{m}$.

Table 1 Expression of pol $\beta$ protein in EC and adjacent esophageal tissue

\begin{tabular}{|c|c|c|c|c|c|c|c|}
\hline \multirow{2}{*}{ Groups } & \multirow{2}{*}{$N$} & \multicolumn{4}{|c|}{ Pol $\beta$ protein } & \multirow{2}{*}{$\begin{array}{c}\text { Strong positive } \\
\text { expression rate }(\%)\end{array}$} & \multirow{2}{*}{$P$-value } \\
\hline & & - & + & ++ & +++ & & \\
\hline Adjacent normal tissue & 114 & 0 & 101 & 13 & 0 & 0.00 & \\
\hline \multicolumn{8}{|l|}{ Age(years) } \\
\hline$\geqslant 60$ & 51 & 0 & 3 & 27 & 21 & 39.62 & \\
\hline$<60$ & 63 & 0 & 6 & 27 & 30 & 47.62 & 0.608 \\
\hline \multicolumn{8}{|l|}{ Gender } \\
\hline Male & 53 & 0 & 3 & 27 & 23 & 43.40 & \\
\hline Female & 61 & 0 & 6 & 27 & 28 & 45.90 & 0.937 \\
\hline \multicolumn{8}{|l|}{ Lymph node metastasis } \\
\hline Yes & 45 & 0 & 0 & 15 & 30 & 66.67 & \\
\hline No & 69 & 0 & 9 & 39 & 21 & 30.43 & $<0.001$ \\
\hline
\end{tabular}



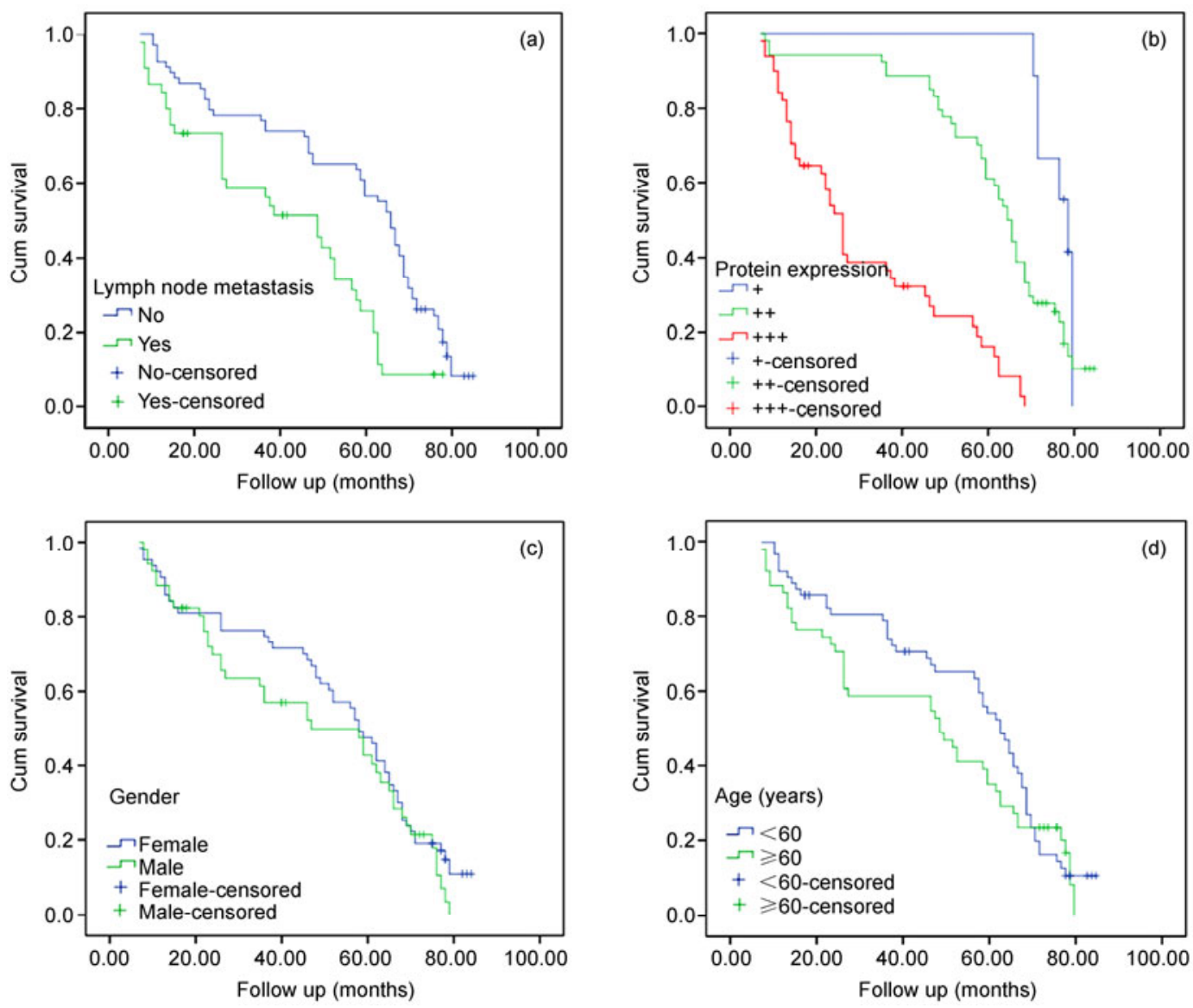

Figure 3 Survival analysis of EC patients. Comparison of survival curve between esophageal cancer patients with and without lymph node metastasis (a). Comparison of survival curve between esophageal cancer patients different in protein expression (b). Comparison of survival curve between esophageal cancer patients different in sex (c) and in age (d).

(Wald $\chi^{2}=1.135, P=0.287$ ). COX multivariate regression analysis further proved that the risk factors in survival of esophageal cancer patients included the presence of lymph node metastasis (Wald $\chi^{2}=12.370, P<0.001$ ) and the high expression in either pol $\beta$ mRNA (Wald $\chi^{2}=111.934, P<$ 0.001 ) or pol $\beta$ protein (Wald $\chi^{2}=47.046, P<0.001$ ), but not sex or age.

\section{Discussion}

DNA pol $\beta$, the core of the base excision system, exists widely within nucleus of mammalian cells, it works as a lyase capable of splitting the deoxynucleotide residue at the $5^{\prime}$ end $\left(5^{\prime} \mathrm{dRP}\right)$ and synthesizes the deoxynucleotide breach formed after base excision. DNA pol $\beta$ normal biological condition remains a low and permanent level, with the main function of reparation. Based on previous research, DNA pol $\beta$ has the indispensable action in repairing endogenous DNA oxidative damage, spontaneous depurination and depyrimidine, and DNA base damage induced by exogenous harms [13-15]. Early observations indicated the overex- pression of pol $\beta$ in some cancers [16-18]. Albertella and co-workers used expression arrays to study systematically the expression patterns of BER (base excision repair) DNA polymerases in cancer cells [11]. They found that the major BER DNA polymerase, pol $\beta$, was overexpressed in approximately one-third of all tumors sampled and $\operatorname{pol} \beta$ was most frequently overexpressed in cancers in vivo of uterus, ovary, prostate and stomach.

Our group has carried out series of researches focused on expression of DNA pol $\beta$ in esophageal cancer, and one of our findings is the high expression of pol $\beta$ in esophageal tumors, which correlates to drug-resistance of this malignancy [19-22]. In this research, we analyzed the clinical and pathological significance of $\operatorname{pol} \beta$ as well as its correlation to survival of the patients, through testing its expression in both esophageal tumors and the matched normal tissues adjacent to tumor. RT-qPCR and protein IHC found a significantly higher expression of pol $\beta$ in esophageal tumor than in its matched adjacent esophageal tissue, and higher expression of pol $\beta$ mRNA with significance in esophageal tumors with lymph node metastasis than in those without it. Logistic regression implied the relative expression of pol $\beta$ 
mRNA to be the risk factor of lymph node metastasis of the patients. $100 \%$ of positive expression of pol $\beta$ protein was observed in either esophageal tumors or the matched normal tissues. The rate of the strong positive of pol $\beta$ protein expression was $44.73 \%$ in the esophageal tumor, higher statistically than that in the matched normal tissue. In the 45 tumors with lymph node metastasis, the rate of $66.67 \%$ of the strong positive of pol $\beta$ protein expression was noticed, significantly higher than the $30.43 \%$ observed in the 69 tumors without the metastasis. Kaplan-Meier survival analysis was made, based on follow up of the 114 subjects with esophageal cancer. Log-rank test revealed the significant difference in survival curve either between patients with the lymph node metastasis and those without it, or between patients with different levels $(+,++$ and +++$)$ of positive expression of pol $\beta$ protein, but not between groups different in sex or ages $(\geqslant 60$ years and $<60$ years). Based on COX univariate or multivariate regression analysis, the risk factors of survival of esophageal cancer patients were considered to be the presence of metastasis, level of pol $\beta$ mRNA expression and pol $\beta$ protein, but not sex or age.

These findings suggest the probable improvement of oncogenesis and development by DNA pol $\beta$ in esophageal cancer, which may be explained by the overly expressed $\operatorname{pol} \beta$ alters the distribution of normal functions and active status of various DNA pol $\beta$. The DNA pol $\beta$ existing in high percentage will replace other DNA polymerases and fulfills its function of DNA polymerization, which is its minor action, to participate in DNA replication. Given its poor fidelity in replication without text-proofing, the overly expressed will lead to the replication with errors of genes mediating cell cycle and the accumulation of mutations in a static cell [23]. Meanwhile, mutual action between the highly expressed DNA pol $\beta$ and telomeric repeat binding factor2 (TRF2) will disturb the function of telomeres and the melted ends of chromosomes, thereby raising the hereditary instability, increasing the spontaneous mutation rate and promoting oncogenesis [24]. High expression of pol $\beta$ in esophageal cancers is often accompanied with mutation of pol $\beta$, which lowers the sensitivity of the malignancy to radiotherapy and chemotherapy [25-28]. Maybe it is another important reason of the influenced development of esophageal and survival by the expression level of DNA pol $\beta$.

In short, our results imply that overexpression of DNA pol $\beta$ may be a potential bio-marker in favor of early-stage diagnosis and indicating the poor prognosis in human esophageal cancer. Though a clue is provided for oncogenesis and development of this malignancy, this research is limited by the small sample size used in analysis on DNA pol $\beta$ expression and follow. Our successive research based on a larger sample is still needed to elucidate the mechanism of pol $\beta$ in esophageal cancer, and therefore provide a basis for the controlled expression of pol $\beta$ within the proper range, inhibition of the development of esophageal cancer, and improved efficacy of radiotherapy and chemotherapy.

We thank Dr. Qi YiJun and Prof. Huangfu ChaoShen for their generous help. This work was supported by the National Natural Science Foundation of China (39870287 and 81100759) and Natural Science Foundation of Henan University (2010ZRZD02).

1 Zheng S, Vuitton L, Sheyhidin I, et al. Northwestern China: A place to learn more on oesophageal cancer. Part one: Behavioural and environmental risk factors. Eur J Gastroenterol Hepatol, 2010, 22: 917-925

2 He Y T, Hou J, Chen Z F, et al. Trends in incidence of esophageal and gastric cardia cancer in high-risk areas in China. Eur $\mathrm{J}$ Cancer Prev, 2008, 17: 71-76

3 Zhang B H, Yang W J, Wang Y G, et al. Clinical manifestation and prognosis of the surgical treatment of esophageal carcinosarcoma (in Chinese). Zhonghua Wai Ke Za Zhi, 2012, 50: 256-259

4 Zhu S C, Song C L, Shen W B, et al. Prognostic analysis of clinicopathological factors in patients after radical resection of esophageal carcinom (in Chinese). Zhonghua Zhong Liu Za Zhi, 2012, 34: 281-286

5 Hoeijmakers J H. Genome maintenance mechanisms for preventing cancer. Nature, 2001, 411: 366-374

6 Lan L, Nakajima S, Oohata Y, et al. In situ analysis of repair processes for oxidative DNA damage in mammalian cells. Proc Natl Acad Sci USA, 2004, 101: 13738-13743

7 Beard W A, Wilson S H. Structure and mechanism of DNA polymerase beta. Chem Rev, 2006, 106: 361-382

8 Prasad R, Batra V K, Yang X P, et al. Structural insight into the DNA polymerase beta deoxyribose phosphate lyase mechanism. DNA Repair, 2005, 4: 1347-1357

9 Cabelof D C, Ikeno Y, Nyska A, et al. Haplinsufficiency in DNA polymerase beta increase cancer risk with age and alters mortality rate. Cancer Res, 2006, 66: 7460-7465

10 Luo Q, Lai Y, Liu S, et al. Deregulated expression of DNA polymerase $\beta$ is involved in the progression of genomic instability. Environ Mol Mutagen, 2012, 53: 325-333

11 Albertella M R, Lau A, O'Connor M J. The overexpression of specialized DNA polymerases in cancer. DNA Repair (Amst), 2005, 4: 583-593

12 Srivastava D K, Husain I, Arteaga C L, et al. DNA polymerase beta expression differences in selected human tumors and cell lines. Carcinogenesis, 1999, 20: 1049-1054

13 Matsuda T, Bebenek K, Masutani C, et al. Low fidelity DNA synthesis by human DNA polymerase-eta. Nature, 2000, 404: 1011-1013

14 Polosina Y Y, Rosenquist T A, Grollman A P, et al. 'Knock down' of DNA polymerase beta by RNA interference: Recaptulation of null phenotype. DNA Repair, 2004, 3: 1469-1474

15 Wilson D M, Thompson L H. Life without DNA repair. Proc Natl Acad Sci USA, 1997, 94: 12754-12757

16 Srivastava D K, Husain I, Arteaga C L, et al. DNA polymerase beta expression differences in selected human tumors and cell lines. Carcinogenesis, 1999, 20: 1049-1054

17 Tan X H, Zhao M, Pan K F, et al. Frequent mutation related with overexpression of DNA polymerase beta in primary tumors and precancerous lesions of human stomach. Cancer Lett, 2005, 220: 101114

18 Chan K K, Zhang Q M, Dianov G L. Base excision repair fidelity in normal and cancer cells. Mutagenesis, 2006, 21: 173-178

19 Zhao J, Liu K, Lu J, et al. Alternariol induces DNA polymerase $\beta$ expression through the PKA-CREB signaling pathway. Int J Oncol, 2012, 40: 1923-1928

20 Zhao G Q, Wang T, Zhao Q, et al. Mutation of DNA polymerase beta in esophageal carcinoma of different regions. World J Gastroenterol, 2005, 11: 4618-4622

21 Dong Z M, Zheng N G, Wu J L, et al. Difference in expression level and localizati on of DNA polymerase beta among human esophageal 
cancer focus, adjacent and corresponding normal tissues. Dis Esophagus, 2006, 19: 172-176

$22 \mathrm{Li} \mathrm{M}$, Zang W Q, Fu Q, et al. Correlation bet ween overexpressi on of DNA polymerase beta gene and drug resistence of human esophageal carcinoma cells. J Fourth Mil Med Univ, 2007, 28: 1065-1068

23 Bergoglio V, Pillaire M J, Lacroix-Triki M, et al. Deregulated DNA polymerase beta induces chromosome instability and tumorigenesis. Cancer Res, 2002, 62: 3511-3514

24 Fotiadou P, Henegariu O, Sweasy J B. DNA polymerase beta interacts with TRF2 and induces telomere dysfunction in a murine mammary cell line. Cancer Res, 2004, 64: 3830-3837

25 Neijenhuis S, Verwijs-Janssen M, van den Broek L J, et al. Targeted radiosensitization of cells expressing truncated DNA polymerase beta. Cancer Res, 2010, 70: 8706-8714

26 Tang J B, Goellner E M, Wang X H, et al. Bioenergetic metabolites regulate base excision repair-dependent cell death in response to DNA damage. Mol Cancer Res, 2010, 8: 67-79

27 Vens C, Hofland I, Begg A C. Involvement of DNA polymerase beta in repair of ionizing radiation damage as measured by in vitro plasmid assays. Radiat Res, 2007, 168: 281-291

28 Bergoglio V, Canitrot Y, Hogarth L, et al. Enhanced expression and activity of DNA polymerase beta in human ovarian tumor cells: Impact on sensitivity towards antitumor agents. Oncogene, 2001, 20: $6181-6187$

Open Access This article is distributed under the terms of the Creative Commons Attribution License which permits any use, distribution, and reproduction in any medium, provided the original author(s) and source are credited. 